\title{
Quantitative studies on heterosis and inbreeding depression in maize (Zea mays L.)
}

\author{
Ranju Kumari ${ }^{*}$, A. K. Singh ${ }^{2}$ and Sugandh $\operatorname{Suman}^{2}$ \\ ${ }^{1}$ Department of Plant Breeding and Genetics, Nalanda College of Horticulture, Noorsarai, Nalanda, \\ B.A.U., Sabour, Bhagalpur, INDIA \\ ${ }^{2}$ Dr Rajendra Prasad central Agricultural University, Bihar, Pusa, Samastipur-848125, INDIA \\ *Corresponding author. E-mail: ranjupusa@gmail.com
}

Received: March 28, 2017; Revised received: August 5, 2017; Accepted: January 12, 2018

\begin{abstract}
The present investigation was carried out for studying heterosis and inbreeding depression of twenty eight hybrids $\left(F_{1}\right.$ s $)$ and their $F_{2}$ 's made by crossing of eight maize inbreds in all possible cross combinations excluding reciprocal. Observations were recorded on ten quantitative traits viz., plant height $(\mathrm{cm})$, ear length $(\mathrm{cm})$, ear girth $(\mathrm{cm})$, number of kernel rows per ear, number of kernels per row, 100 kernels weight $(\mathrm{g})$ yield per plant $(\mathrm{g})$, days to $50 \%$ tassel emergence, days to $50 \%$ silk emergence and days to $50 \%$ maturity. Variable magnitude of heterosis was observed for different cross combinations for all the traits. Based on higher mean performance (94.33 to 118.67 $\mathrm{g} / \mathrm{plant}$ ) and higher heterotic response (11.95 to 30.48\%) eleven crosses were selected. Response of inbreeding depression was significant in positive direction for most of the traits. Among these eleven crosses five crosses CM 300 x CML 142, CM 300 x CML 144, CM 300 x CML 150, CM 300 x CML 176 and CML 150 x CML 144 were selected having high heterotic value (12.31 to $30.48 \%$ ) and lower inbreeding depression (less than $15 \%$ ) for their utilization in maize improvement programme for the development of superior inbred lines.
\end{abstract}

Keywords: Heterotic value, Inbreeding depression, Maize, Quantitative studies, Zea mays

\section{INTRODUCTION}

Maize is the third most important cereal crop in India after rice and wheat. It accounts for $\sim 9$ per cent of total food grain production in the country. Its production in India has grown from $14 \mathrm{MnMT}$ in 2004-05 to 23 MnMT in 2013-14 maintaining the growth rate of 5.6 per cent over the last ten years (Agricultural Statistics at a glance, 2014). Being a multipurpose crop as food, feed and having industrial value, it is also known as miracle crop or queen of the "cereals". In case of maize, a great scope for the genetic improvements are available, due to presence of variability in their germplasm (Om Prakash et al., 2006). Knowledge on different traits of interest (qualitative and quantative traits) and their genetic control is a pre-requisite for planning the genetic improvement strategies (Premlatha and Kalamani, 2009). For improving the genetic architecture of the crop through breeding efforts, utilization of heterosis is important for maximization of the yield in maize. Heterosis response is expressed as a deviation of the performance of $F_{1}$ (cross) from either of the parents (better parents heterosis) or average of the parental value (mid parent heterosis). But for commercial exploitation of heterosis, known as standard heterosis was estimated as deviation of the performance of hybrid from the standard variety using as check. Standard heterosis was mostly considered for release of new hybrids. Nowadays, the maize breeder are emphasizing on single cross hybrids for better grain yield, uniformity, low cost of hybrid seed production and availability of superior and diverse inbred lines (Premlatha and Kalamani, 2009; Singh et al., 2010; Kumari et al., 2016). Inbreeding involves mating together of individuals that are closely related by ancestry in comparison to random mating. Consequence of inbreeding is the reduction in mean phenotypic value of the characters related with reproductive capacity or physiological efficiency is termed as "inbreeding depression". The present investigation has been undertaken to study the heterosis in $\mathrm{F}_{1}$ over standard check (SC) and inbreeding depression over $\mathrm{F}_{2}$ segregating generation for yield and its related characters in maize. Since, inbreeding depression and heterosis are completely opposite in terms of their manifested effect. It is essentially required to generate precise information on heterosis and inbreeding depression with respect to characters, in order to assess the relative potential of experimental hybrids for extraction of inbred.

\section{MATERIALS AND METHODS}

The experiment was conducted at the Research farm of 
Tirhut College of Agriculture, Dholi, under Rajendra Agricultural University, Bihar, Pusa. Materials for the present investigation were generated from eight inbred lines, including five quality protein maize (QPM) inbreds (CML 142, CML 144, CML 150, CML 176, CML 186) and three non-QPM inbreds (CM 300, CM 400 and CM 600) obtained from AICRP on maize, Dholi Centre. These parental lines were planted in crossing block on different dates with an interval of three days for synchronization of flowering period in order to facilitate crossing programme. Each plot consisted of three rows of five meter length with row to row and plant to plant spacing of 60 and $20 \mathrm{~cm}$ respectively. The inbreds were crossed in all possible combinations excluding reciprocals and 28 crosses were made. $F_{2}$ seeds were generated by selfing the $F_{1}$ plants. The 28 crosses obtained together with the eight parental inbreds, $28 \mathrm{~F}_{2}$ 's and a QPM check Shaktiman-4 were evaluated in randomized block design (RBD) with three replication under timely $\left(19^{\text {th }}\right.$ November $)$ and late sown conditions $\left(17^{\text {th }}\right.$ December $)$. Entries were grown at a spacing of $60 \mathrm{~cm} \mathrm{x} 20 \mathrm{~cm}$ in rows of five meter length in plots having three rows per plot for parents and $F_{1}$ 's whereas, $F_{2}$ 's were grown in plots having five rows per plot. Recommended package of practices was followed to raise a good crop. To obtain the estimates of heterosis and inbreeding depression of 28 crosses ten agronomic traits were assessed. Observations were recorded on whole plot basis for days to 50 per cent tassel emergence, days to 50 per cent silk emergence and days to $50 \%$ maturity by counting the number of days from sowing to the issuance of tassel, silk and maturity of cob in 50 per cent plants. Five randomly selected plants in each plot were used for recording observations on plant height, ear length, ear girth, number of kernel rows per ear, number of kernels per row, 100 kernel weight, yield per plant for parents and $F_{1}$ 's. While, in case of $F_{2}$ 's observations were recorded on twenty five plants chosen randomly in each plot.Statistical analysis was calculated by the mean of individual data recorded for each character in each replication separately for each cross. To make the result more precise and manageable, the result on pooled data basis (across the environment) were presented in order to generate generalized information regarding the extent of heterosis and inbreeding depression in different characters of hybrids evaluated in the present study. Heterosis was calculated over standard check (SC) as percentage increases or decrease of the performance of the traits over standard check variety in desirable direction was calculated using the following formula:

Standard heterosis (SH); (Meredith and Bridge, 1972)

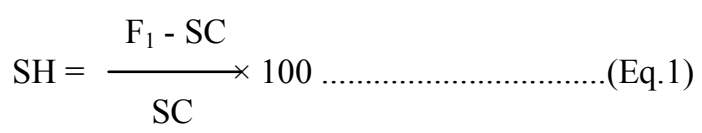

Where, $F_{1}=$ Mean performance of $F_{1}$ hybrid

$\mathrm{SC}=$ Mean performance of standard check

Inbreeding depression (ID) was calculated by using following formula:

$$
\text { ID }=\frac{F_{1}-F_{2}}{F_{2}} \times 100 \quad \ldots \ldots \ldots \ldots \ldots \ldots . .(E q .2)
$$

Where, $F_{1}=$ Mean performance of $F_{1}$ hybrid

$\mathrm{F}_{2}=$ Mean performance of $\mathrm{F}_{2}$

Significance of heterosis and inbreeding depression were determined with a t test.

\section{RESULTS AND DISCUSSION}

Analysis of variance revealed (Table 1) highly significant differences among the treatment for most of the traits.Variance is partitioned in to different sources in order to test the significance of these sources of variation. Highly significant variance for parents $\mathrm{Vs}_{\mathrm{F}_{1}}$ 's were observed for all the characters with the exception of days to $50 \%$ tassel emergence and days to $50 \%$ silk emergence indicating superior performance of hybrids over parents. The mean sum square due to $F_{1}$ 's Vs $F_{2}$ 's was found to be significant for all the characters indicating the occurrence of inbreeding depression in expression of all the characters (Table 1). The effect due to variation in the form of date of sowing was nonsignificant in most of the cases. On the perusal of data in Table 1showed the relative ranking of the genotypes across the date of sowing was influenced to a considerably greater extent for most of the traits including yield per plant. The per se performance of the genotypes revealed that there was substantial variability among them for all the characters. Variable magnitude of heterosis as exhibited by different cross combinations for all the characters indicated sufficient divergence in parental materiel for these traits. Genetic variability among experimental material was also reported by Marker and Krupaker ( 2009), Oliboni et al. (2012), Kumar et al. (2013), Kumari et al. (2013) and other workers.

Reduction in plant height is desirable trait in maize and five crosses estimates significantly lesserplant height in comparison to check among 28 crosses developed. The cross CM 600 x CML 144 ( $-16.52 \%$ ) displayed the most negative heterosis for plant height hence can be used to produce short stature hybrids which can be useful where lodging is a problem. Bhatnagar et al. (2004), Kllaria and Sharma (2006) and Oliboni et al. (2012) earlier reported significant heterosis for dwarfness. None of the crosses appeared to be shorter than the respective shorter parent. Six crosses exhibited significant standard heterosis for earliness in respect of days to $50 \%$ tassel emergence and days to $50 \%$ silk emergence. Out of six crosses, two crosses, CM 600 x CML 186 and CM 600 x CM 300 also exhibited significant standard heterosis for earliness in terms of days to 50\% maturity. Manpreet et al. (2007), Kumar et al. (2008) and Premlatha and Kalamani (2009) observed 
Ranju Kumari et al. / J. Appl. \& Nat. Sci. 10 (1): 64 - 69 (2018)

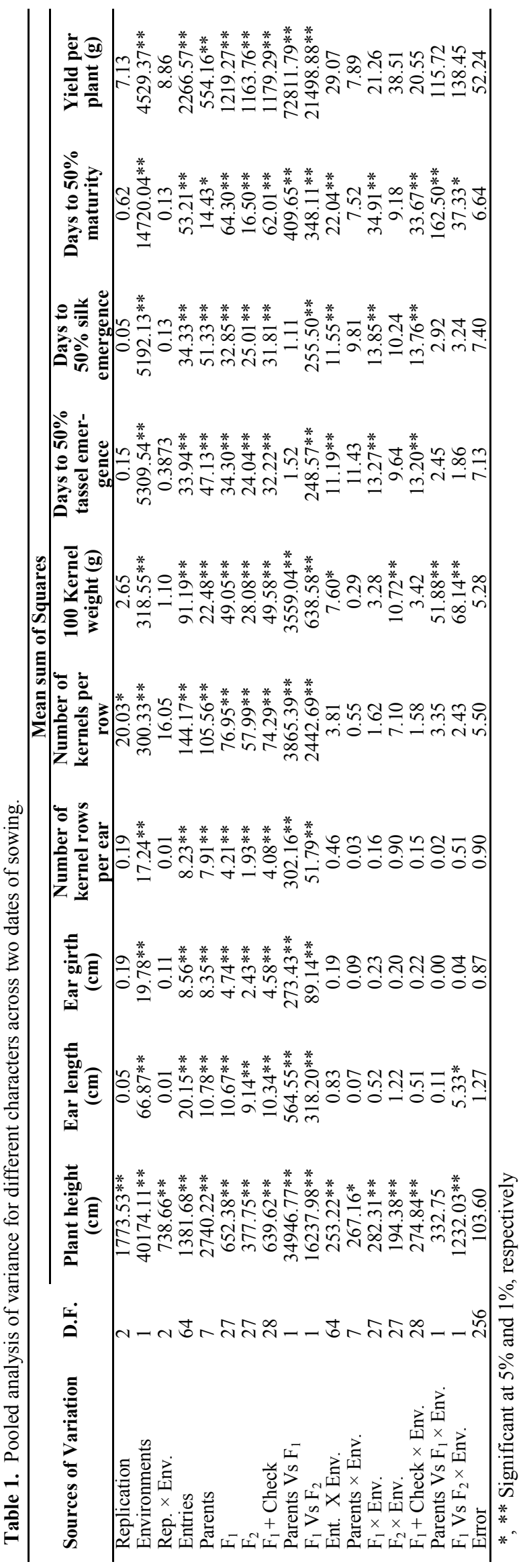

Table 2. Selected best crosses on the basis of per se performance and heterosis (\%) for yield.

\begin{tabular}{lcc}
\hline Hybrid Combinations & Per se performance & Heterosis (\%) \\
\hline CM 300 x CML 144 & 131.75 & $30.48^{* *}$ \\
CM 300 x CML 142 & 131.50 & $30.20^{* *}$ \\
CM 400 x CML 142 & 127.00 & $25.74^{* *}$ \\
CM 142 x CML 186 & 119.42 & $18.23^{* *}$ \\
CM 300 X CML 150 & 118.67 & $17.49^{* *}$ \\
CM 400 x CML 186 & 116.08 & $14.93^{* *}$ \\
CM 400 X CML 176 & 115.00 & $13.86^{* *}$ \\
CM 150 X CML 144 & 114.05 & $12.92^{* *}$ \\
CM 300 X CML 176 & 113.43 & $12.31^{* *}$ \\
CM 186 X CML 144 & 113.43 & $12.31^{* *}$ \\
CM 400 X CML 144 & 113.27 & $11.95^{* *}$ \\
\hline
\end{tabular}

significant heterosis for earliness in terms of days to $50 \%$ tasseling and days to $50 \%$ silking in the case of hybrids included in their studies. Heterosis for earliness in terms of days to $50 \%$ maturity was also reported earlier by Nigussie and Zelleke (2001) and Bhatnagar et al. (2004). Two crosses CM 600 x CML 186 and CM 600 x CM 300 exhibited significant heterosis for earliness as compared to their respective early maturing parent and hence can be used to produce early maturing hybrids. Thirteen crosses were found to have significant standard heterosis for ear length. Cross CM 300 x CML 144 (31.65\%) indicating highest value of heterosis in positive direction. A positive heterotic value, $12.36 \%$ and $10.66 \%$ were observed for two crosses CM $300 \times$ CML 142 and CM $300 \times$ CML 144 respectively which demonstrated a desirable increase in ear girth. Four crosses (CM 400 x CML 176, CM $400 \times$ CML 142, CM $300 \times$ CML 142 and CM $300 \times$ CML 144) exhibit significant standard heterosis ranged from $11.57 \%$ to $15.98 \%$ for number of kernels row per ear revealed increased number of grain rows in a cob. Similar results indicating the manifestation of significantly positive heterosis in these characters have been reportedearlier byKumar et al. (2008), Dubey et al. (2009), Singh et al. (2010) and Kumari et al. (2016) in maize crop. The eleven crosses recorded significantly positive heterosis for number of kernels per row, cross CM $300 \times$ CML 144 showed maximum (23.07\%) heterosis. Significant standard heterosis for 100 kernel weight were recorded to be $9.79 \%$ to $33.24 \%$ in the crosses CM $600 \times$ CML 142 and CM 400 x CM 300, respectively. The eleven crosses registered significant positive standard heterosis, CM300 x CML 142 recorded highest (30.48\%) value. Similar results indicating the manifestation of significantly positive heterosis in these characters in case of maize have been reported earlier by Kumar et al. (2008), Dubey et al. (2009), Singh et al. (2010), Oliboni et al. (2012) and Kumari et al. (2016).

Based on the findings of earlier research, the per se performance of hybrids and the extent of heterosis, in addition to specific combining ability effect are important considerations for commercial exploitation of heterosis. Selection of parents based on any one of 
Ranju Kumari et al. / J. Appl. \& Nat. Sci. 10 (1): 64 - 69 (2018)

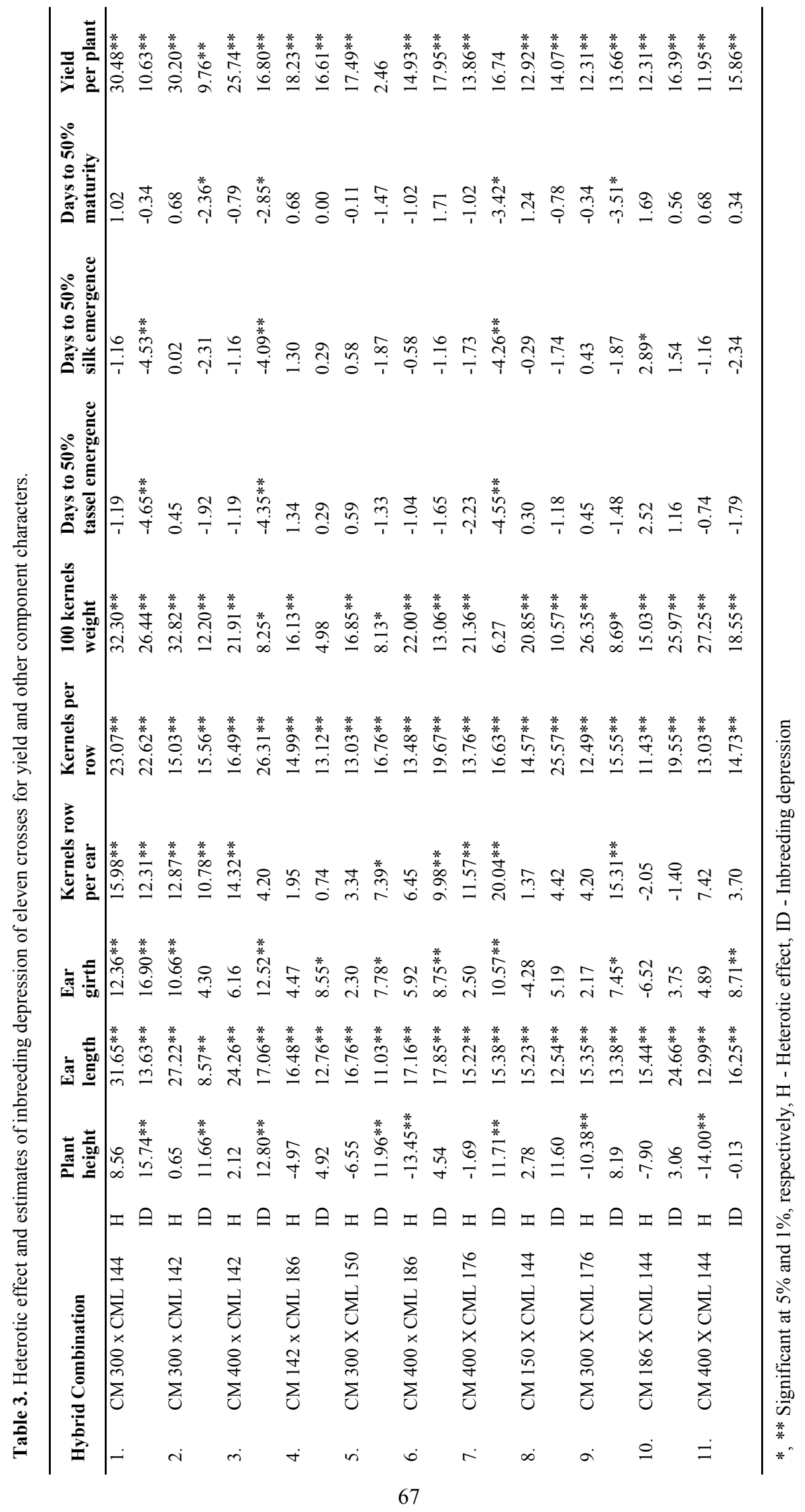


Table 4. Hybrid combinations showing higher mean value and lesser inbreeding depression in $F_{2}$ generation.

\begin{tabular}{|c|c|c|}
\hline Hybrid combinations & $\begin{array}{l}\text { Mean perfor- } \\
\text { mance }\end{array}$ & $\begin{array}{l}\text { Inbreeding } \\
\text { depression }\end{array}$ \\
\hline CM $300 \times$ CML 142 & 118.67 & $9.76^{* *}$ \\
\hline CM 300 x CML 144 & 117.75 & $10.63 * *$ \\
\hline CM $300 \times$ CML 150 & 115.75 & 2.46 \\
\hline CM 400 x CML 142 & 105.67 & $16.80 * *$ \\
\hline CML 142 X CML 186 & 99.58 & $16.61 * *$ \\
\hline CM 300 x CML 176 & 97.93 & $13.66^{* *}$ \\
\hline CML 150 X CML 144 & 97.50 & $14.07 * *$ \\
\hline CM 400 X CML 176 & 95.75 & $16.74 * *$ \\
\hline CM 400 X CML 186 & 95.25 & $17.95 * *$ \\
\hline CML 186 X CML 144 & 94.84 & $16.39 * *$ \\
\hline CM 400 X CML 144 & 94.33 & $15.86^{* *}$ \\
\hline
\end{tabular}

these criteria alone, therefore, may not be purposefully effective. Accordingly, in the present study, for commercial exploitation of heterosis eleven crosses were identified as the best cross combination based on their per se performance and the magnitude of heterosis in trait(s) of economic importance (Table 2). The eleven cross combinations, namely, CM 300 x CML 144, CM 300 x CML 142, CM 400 x CML 142, CML 142 x CML 186, CM 300 x CML 150, CM 400 x CML 186, CM 400 x CML 176, CML 150 x CML 144, CM 300 x CML 176, CM 400 x CML 144 and CML 186 x CML 144 were recorded significantly higher mean performance and significantly positive standard heterosis for yield (Table 3). The result, therefore, revealed that per se performance for yield of hybrids reflected the degree of heterosis manifestation in the hybrids. This is in agreement with the earlier reports made by Dubey et al. (2009), Premlatha and Kalamani (2009), Singh et al. (2010) and Oliboni et al.(2012) in case of maize crop. Among different characters studied, the extent of positive heterosis for yield and associated traits of selected crosses are presented in Table 3. Heterosis for yield is being manifested as the cumulative effect of heterosis of component traits. In the present investigation, the study of selected crosses on their per se revealed that the most of crosses that showed positive and significant heterosis for yield also showed heterosis for ear length, ear girth, kernels row per ear, kernels per row and 100 kernels weight. Similar findings have been reported for these characters in maize crop earlier by Kumar et al. (2008), Premlatha and Kalamani (2009) and Singh et al. (2010). The characters like ear girth, 100 seed weight and number of kernel row per ear are known to exhibit highest correlation with grain yieldin maize reported by Sofi et al. (2007) and Kumari et al. (2016). The per se performance were in general related to the heterotic response for majority of characters were also reported in rice (Kumari et al., 2014 ) and in tomato (Kumar and Singh, 2016).

One of the characteristics of heterosis is that the increase in vigour is confined to $F_{1}$ generation. There is considerable depression from $F_{1}$ to $F_{2}$ and later gener- ation. Shull (1914) reported that high inbreeding depression (positive) is the reflection of higher heterosis especially in cross-pollinated crop like maize. It may be seen from the present study that hybrid combinations that showed higher estimates of heterosis in general found to show substantial inbreeding depression (Table 3). In maize, inbreeding is accompanied by a reduction in the mean phenotypic value of most of the traits of economic importance simply because of reduction in fitness. Value of significantly positive inbreeding depression for plant height varied between $11.60 \%$ to $15.74 \%$. Low inbreeding depression for plant height in positive direction was also reported earlier in maize by Maldonado and Miranda Filho (2002) and Kllaria and Sharma (2006). The $F_{2}$ population derived from these crosses recorded positive estimate of inbreeding depression for plant height hence helpful in screening of transgressive segregants from $\mathrm{F}_{2}$ population having reduced plant height. The $\mathrm{F}_{2}$ population derived from the cross CML 186 x CML 144 recorded positive and useful estimate of inbreeding depression for days to $50 \%$ silking indicating earliness for days to silking. The results, therefore, suggested that formation of new gene combination as a result of segregation and recombination may lead to increase in the degree of expression of a trait in the $F_{2}$ population. The statistically significant values of inbreeding depression for ear length, ear girth, number of kernel rows per ear, number of kernels per row, 100 kernels weight and grain yield per plant ranged between 8.51 to $24.66,7.45$ to $16.90,7.39$ to $20.04,13.12$ to 25.57 , 8.13 to 26.44 and 9.76 to $17.95 \%$, respectively. Less inbreeding depression for yield attributing traits viz., ear diameter, number of rows per ear and number of kernels per row was reported earlier by San Vicente and Hallauer (1993). High inbreeding depression for yield in maize was reported by many workers (Singh and Khalidi, 2002 Aramendiz et al., 2004; Simon et al., 2004; Andreoli et al., 2006; Kumari, 2013).

Hybrids are considered to possess a high degree of biological fitness for a given situation. Inbreeding tends to disrupt this fitness. Crosses which tolerate this stress are desirable from the stand point of forming a heterotic group. Inbreeding tolerant base population could be used to generate inbred lines extract inbred lines as well as for the development of commercially promising single cross hybrids. In the present study, five crosses, namely, CM 300 x CML 142, CM 300 x CML 144, CM 300 x CML 150, CM $300 \times$ CML 176 and CML $150 \times$ CML 144 having higher heterosis, inbreeding depression less than $15 \%$ and high mean performance in $\mathrm{F}_{2}$ generation were identified for their further utilization in recombination breeding programmes (Table 4).

\section{Conclusion}

It was concluded that among 28 crosses which were generated from all possible cross combinations exclud- 
ing reciprocal from eight genetically diverse parents, the eleven cross combinations were recorded significantly higher mean performance and significantly positive standard heterosis for yield. It was observed that in most of the cases, heterosis manifestation in grain yield was found to be associated with simultaneous heterosis in ear length, number of kernels per row and 100 kernel weight. Keeping greater magnitude of heterosis, higher mean performance and lesser inbreeding depression (less than 15\%) into consideration, five crosses, namely, CM 300 x CML 142, CM 300 x CML 144, CM $300 \times$ CML 150, CM $300 \times$ CML 176 and CML 150xCML 144 were identified. These five crosses may be further used in maize improvement programme for the development of superior inbred lines.

\section{ACKNOWLEDGEMENTS}

Present investigation is based on a part of $\mathrm{Ph} . \mathrm{D}$. thesis. The senior author is thankful to the All India Coordinated Project on Maize, Dholi centre, RAU, Pusa , Bihar for providing the materials and labourers for carrying out the field works of the present studies.

\section{REFERENCES}

Agricultural Statistics at a glance (2014). Agricultural Statistics Division, Directorate of Economics and Statistics, Department of Agriculture and Co-operation, Ministry of Agriculture, Govt. of India.

Andreolic, C. Carvalho, C.C. and Andrade, R.V. de. (2006). Yield losses due to inbreeding and the use of molecular markers (RAPD) for assessment of genetic purity in hybrid corn (Zea mays L.). Revista Brasileira-de-Milho -e-Sorgo, 5 (1) : 1-14.

Aramendiz Tatis, H., Espitia Camacho, M. and Navarro Ramos, G.( 2004). Inbreeding depression of maize hybrids (Zea mays L.) in the SinuVollay of Colombia. Agricultura- Tecnica - en - mexico, 30 (2) : 139-144.

Bhatnagar, S., Betran, F.J. and Rooney, L.W. (2004). Combining abilities of quality protein maize inbreds. Crop Science, 44 (6) : 1997-2005.

Dubey, R.B., Joshi, V.N. and Verma, M. (2009). Heterosis for nutritional quality and yield in conventional and non -conventional hybrids of maize (Zea mays L.). Indian $J$. Genet., 69 (2) : 109-114.

Kllaria, R.K. and Sharma, A.K.( 2006). Heterobeltiosis and inbreeding depression in barley (Hordeum Vulgare L.) Indian J. Genet., 66 (1) : 41-42.

Kumar, P., Godawat, S.L., Vyas, M. and Pandiya,N.K. (2008). Performance of maize (Zea mays) genotypes in different ecological systems. Indian Journal of Agricultural Sciences, 78 (11) : 939-42.

Kumar, P.P. and Satyanarayana, E. (2006). Heterosis for yield and yield components in full season maize genotypes. Indian Journal of Dryland Agricultural Research and Development, 21 (1) : 88-90.

Kumar, C. and Singh, S. P. (2016). Heterosis and inbreeding depression to identify superior $\mathrm{F}_{1}$ hybrids in tomato (Solanum lycopersicum L.) for yield and its contributing traits. Journal of Applied and Natural Science, 8 (1) : 290-296

Kumar, R. S., Shahi, J. P. and Srivastava, K. (2013). Estima- tion of heterosis in field corn and sweet corn at marketable stage. The Bioscan. 8 (4):1165-1170.

Kumari, R. (2013). Manifestation of heterosis in relation to ggenetic divergence and isozyme pattern in maize (Zea mays L.). Thesis submitted to Rajendra Agricultural University, Bihar, Pusa for award the Ph. D. Degree.

Kumari, P., Jaiswal, H. K. and Woza, S. K. (2014). Combining ability and heterosis for yield, its component traits and some grain quality parameters in rice (Oryza sativa L.), Journal of Applied and Natural Science, 6(2):495-506

Kumari, R., Singh, A. K., and Sharma, V. K. (2016). Heterosis and genetic divergence correlation studies for yield and its related traits in maize (Zea mays L.). The Bioscan, 11 (3) : 1849-1854

Maldonado, F.A.A. and Miranda Filho, J.B. de. (2002). Inbreeding depression in maize population of reduced size. Scientia Agricola, 59 (2) : 335-340.

Manpreet, B., Verma, S.S., Kumar, A., Kabdal, M.K., Aditya, J.P. and Ashish, N. (2007). Combining ability analysis and heterosis estimates in high quality protein maize inbred lines. Indian Journal of Agricultural Research, 41 (1) : 49-53.

Marker, S. and Krupakar, A. (2009). Genetic divergence in exotic maize germplasm (Zea mays L.). ARPN Journal of Agricultural and Biological Science, 4 (4) : 44-46.

Meredith, W. R. and Bridge, R. R. 1972. Heterosis and gene action in cotton Gossipium hirsutam. Crop Sci. 12: 304-310

Nigussie, M. and Zelleke, H. (2001). Heterosis and combining ability in a diallel among eight elite maize population. African Crop Science Journal, 9 (3) : 471-479.

Oliboni, R., Faria, M. V., Neumann, M., Battistelli, G. M., Tegoni, R. T. G. and Resende, J. T. V. de. (2012). Genetic divergence among maize hybrids and correlation with heterosis and combining ability. Acta Scientiarum. 34(1): 37-44

Om Prakash, Shanti P., Satyanarayan E. and Saikumar R. 2006. Exploitation of genetic variability for quality traits and agronomic characters in quality protein maize (QPM) germplasm (Zea mays L.) Ann. Agric. Res. New Series, 27 (3) : 240-244.

Premlatha, M. and Kalaman,i A.( 2009). Heterosis and combining ability studies for grain yield and its related traits in maize (Zea mays L.). Maysore J. Agric. Sci., 43(1):62-66

San Vicente, F.M. and Hallauer A.R. (1993). Inbreeding depression rates of materials derived from two groups of maize inbred lines. Revista Brasileira de Genetica, 16 (4) : 989-1001.

Shull G.H.(1914).Duplicate genes for capsule form in Bursabursa pastoris. Z. Ind. Abst.Vereb, $12: 97-149$.

Simon, G.A., Scapim, C.A., Pacheco, C.A.P., Pinto, R.J.B., Braccin,i A. de L.E. and Tonet, A.(2004). Inbreeding depression in popcorn population.Bragantia,63(1):55-62

Singh, A.K., Shahi, J.P. and Rakshit, S. (2010). Heterosis and combining ability for yield and its related traits in maize (Zea mays ) in contrasting environments. Indian Journal of Agricultural Sciences, 80 (3) : 248-249.

Singh, R.D. and Khalid,i G.A. (2002). Inbreeding depression in synthesized population of maize (Zea mays L.). New Botanist, 29 ( 1/4 ) : 141-148.

Sofi, P.A., Rathe,r A.G. and Zahoor, D. (2007). Association of heterosis expression for grain yield and its component trait in maize (Zea mays L.) International Journal of Agricultural Research, 2 (5) : 500-503. 